\title{
ADSORPTION OF PROCION RED USING LAYER DOUBLE HYDROXIDE Mg/Al
}

\author{
Muhammad Imron ${ }^{1}$, Muhammad Said ${ }^{1}$, Aldes Lesbani ${ }^{1 *}$ \\ ${ }^{1}$ Department of Chemistry, Faculty of Mathematic and Natural Sciences, Sriwijaya University \\ *Corresponding Author E-mail : aldeslesbani@yahoo.com
}

\begin{abstract}
Layer double hydroxide $\mathrm{Mg} / \mathrm{Al}$ was synthesized by inorganic synthetic method. Material was characterized using FTIR and XRD analyses and used as adsorbent of procion red dye in aqueous medium. Factors that affect the adsorption process are adsorption time as the kinetic parameter; and the temperature and concentration of procion red as the thermodynamic parameter. FTIR spectra of layer double hydroxides showed unique vibration at wavenumber $1300 \mathrm{~cm}^{-1}$ and $1600 \mathrm{~cm}^{-1}$. Characterization using XRD shows diffraction angles at $29^{\circ}, 27^{\circ}$, and $28^{\circ}$, which are typical of $\mathrm{Mg} / \mathrm{Al}$ double layer hydroxides. Adsorption of procion red using layer double hydroxide $\mathrm{Mg} / \mathrm{Al}$ resulted adsorption rate 7.1 minutes $^{-1}$, maximum adsorption capacity $111.1 \mathrm{mg} / \mathrm{g}$ at $60{ }^{\circ} \mathrm{C}$ with increasing energy by increasing adsorption temperature.
\end{abstract}

Keywords: Layered double hydroxides, adsorption, procion red.

\section{INTRODUCTION}

Layered or clay materials are inorganic minerals commonly found in nature and can also be synthesized in laboratories (Centi and Perathoner, 2008). Modification of layered material such as impregnation, grafting, or ion exchange is useful for the application i.e. as catalysts, adsorbents, sensors, membranes or ion exchangers. Layered material was utilized as catalyst for example used for crude petroleum process (Corma, 1997). The use as an adsorbent of layered material used for adsorption addictive in vegetable oil and its application on the control of contamination of metal ions or organic compounds in the environment. The use of the layered material still has small surface area constraints and narrow layer spacing due to the small exchange ions which are generally alkaline and alkaline earth metal ions (Goodarzi et al, 2016).

Meanwhile, the modification materials in the laboratory have many advantages i.e. less impurities and the structure is easy to replace so it can be modified and widely applied as adsorbent or catalyst for example double layer hydroxy. Aside from being an absorbent and a catalyst, double layer hydroxides is usually applied as ion exchangers, catalyst carriers, in industry, and medicine (Xie et al, 2006). For example, a double layer hydroxides material commonly used as a catalyst for condensation reactions is $\mathrm{Mg} /$ $\mathrm{Al}$ hydrotalcite $(\mathrm{Mg} / \mathrm{Al}$ mole ratio in the range of 2.1 to 3.6) with carbonate and nitrate anions in interlayer space (Said and Palapa, 2016). Double layer hydroxides material is also widely used in the adsorption process of heavy metals and dyes in aqueous medium (Hassani et.al, 2017; Asiabi et.al, 2017).

In the industrial field, most of the dyes that have been used will be discharged into the environment. Generally, the dyestuff from the textile industry waste is an organic compound which has an aromatic structure so it is difficult to degrade naturally and certain-

\section{Article History}

Received: 23 December 2016

Received in revised form: 16 June 2017

Accepted: 20 June 2017

DOI: 10.26554/sti.2017.2.3.64-67

(C)2017 Published under the term of the CC BY NC SA license ly not environmentally friendly (Ba-Abbad, et al. 2017). The red procion color of the application will be difficult to remove due to the strong covalent bond between the carbon atoms of the dye and the $\mathrm{O}, \mathrm{N}$, or $\mathrm{S}$ atoms of the hydroxy, amino or thiol groups of the polymer. Therefore, the dy red procion dye has excellent washing resistance. The red procion is used as an adsorbate because the absorption spectra are pointy and clear, the structure is relatively simple, and the color is brighter (Rodrigues et.al, 2009). Factors affecting the adsorption process include the effect of adsorption time, and the influence of temperature and concentration.

\section{EXPERIMENTAL SECTION}

\section{Equipments}

The equipments used in this research are a set of laboratory glass standard such as reflux flask, glass beaker, erlenmeyer, analytical balance, magnetic stirrer, thermometer, hot plate, oven, vacuum, and desiccator. Instruments for analysis and characterization were used such as X -Ray Diffraction (Rigaku Miniflex 600), FT-IR spectrophotometer (Shimadzu prestige-21), and Thermo Scientific spectrophotometer UV-Visible Genesys ${ }^{\mathrm{TM}} 20$.

\section{Materials}

The materials used in this research are sodium phosphate $\left(\mathrm{Na}_{3} \mathrm{PO}_{4}\right)$, sodium tungstate $\left(\mathrm{Na}_{2} \mathrm{O}_{4} \mathrm{~W}\right)$, hydrochloric acid $(\mathrm{HCl})$, potassium hydroxide $(\mathrm{KOH})$, potassium chloride $(\mathrm{KCl})$, diethyl ether $\left(\left(\mathrm{C}_{2} \mathrm{H}_{5}\right)_{2} \mathrm{O}\right)$, sodium hydroxide $(\mathrm{NaOH})$, sodium carbonate $\left(\mathrm{Na}_{2} \mathrm{CO}_{3}\right)$, magnesium nitrate $\left(\mathrm{Mg}\left(\mathrm{NO}_{3}\right)_{2}\right)$, aluminum nitrate ( $\mathrm{Al}(-$ $\left.\left.\mathrm{NO}_{3}\right)_{3}\right)$, and procion red dye $\left(\mathrm{C}_{15} \mathrm{H}_{15} \mathrm{~N}_{3} \mathrm{O}_{2}\right)$. All chemicals are directly used from Merck and Sigma Aldrich without further treatment.

\section{Synthesis of Mg/Al Double Layer Hydroxides}

The synthesis of double layer hydroxides was carried out by mixing $64.01 \mathrm{~g}$ of $\mathrm{Mg}\left(\mathrm{NO}_{3}\right)_{3} \cdot 6 \mathrm{H}_{2} \mathrm{O}$ and $46.64 \mathrm{~g}$ of $\mathrm{Al}\left(\mathrm{NO}_{3}\right)_{3} \cdot 9 \mathrm{H}_{2} \mathrm{O}$ into $150 \mathrm{~mL}$ of water (solution A). A total of $\mathrm{NaOH}$ with $26.62 \mathrm{~g}$ $\mathrm{NaCO}_{3}$ was dissolved in $150 \mathrm{~mL}$ water (solution $\mathrm{B}$ ). Solution A is added to solution $\mathrm{B}$ and stirred slowly followed by the addition of $100 \mathrm{~mL}$ of water. $\mathrm{pH}$ was adjusted ranging from 9 to 10 to form a precipitate. The obtained precipitate is dried in an oven at $80^{\circ} \mathrm{C}$ overnight. Characterization was conducted using FT-IR spectroscopy, and XRD analysis. 


\section{Adsorption of Procion Red}

\section{Effect of Adsorption Time}

A total of $0.05 \mathrm{~g}$ of double layer hydroxides as adsorbent was added to $50 \mathrm{~mL}$ procion red with a concentration of $25 \mathrm{mg} / \mathrm{L}$ and then stirred with a horizontal shaker at predetermined intervals. Variation of adsorption time starts from 5, 10, 15, 20, 30, 45, 60, 90, and 120 minutes. Procion red that has been through the adsorption process is separated and measured its concentration by using a UV-Vis spectrophotometer.

\section{Effect of Concentration of Procion Red and Temperature Adsorption}

Double layer hydroxides $(0.05 \mathrm{~g})$ was mixed with $50 \mathrm{~mL}$ of procion red solution at concentration $10,25,50,100 \mathrm{mg} / \mathrm{L}$. The mixtures were stirring using horizontal shaker for 1 hour at varying temperatures i.e. $30,40,50,60,70$, and $80^{\circ} \mathrm{C}$. The mixture was then filtered and the procion red solution separated from the adsorbent was measured using a UV-Vis spectrophotometer to determine the residual dye concentration after the adsorption process.

\section{Data analysis}

Double layer hydroxides material was applied in adsorption of procion red dye was studied through the effect of adsorption time, concentration of procion red dye, and temperature adsorption. The adsorption kinetics data is used to determine the adsorption rate by assuming that the adsorption process following the Langmuir-Heinselwood adsorption kinetics equation model is as follows:

$$
\frac{\ln \left(C_{0} / C\right)}{C}=k_{1} \frac{t}{C}+K
$$

where :

$\mathrm{C}_{\mathrm{o}}=$ initial concentration of procion $\mathrm{red}(\mathrm{mg} / \mathrm{L})$

$\mathrm{C}=$ concentration of residual procion $\mathrm{red}(\mathrm{mg} / \mathrm{L})$

$\mathrm{T}=$ adsorption time (minutes)

$\mathrm{K}_{1}=$ adsorption rate $\left(\mathrm{min}^{-1}\right)$

$\mathrm{K}=$ adsorption equilibrium constant

The thermodynamic parameters of the adsorption process of the procion red dye on the double layer hydroxides such as adsorption capacity and adsorption energy can be determined using the following equations:

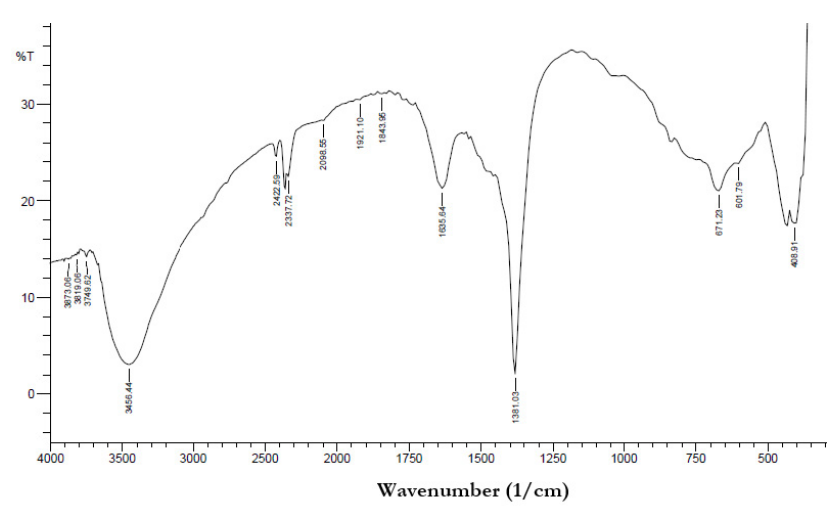

Figure 1. FT-IR spectra of $\mathrm{Mg} / \mathrm{Al}$ double layer hydroxides

$$
\begin{aligned}
& \frac{C}{m}=\frac{1}{b K}+\frac{C}{b} \\
& E=-R T \ln K
\end{aligned}
$$

where:

$\mathrm{C}=$ concentration of residual procion $\mathrm{red}(\mathrm{mg} / \mathrm{L})$

$\mathrm{M}=$ mol procion red adsorbed on double layer hydroxides

$\mathrm{K}=$ equilibrium constant

$\mathrm{B}=$ adsorption capacity $(\mathrm{mol} / \mathrm{g})$

$\mathrm{E}=$ adsorption energy $(\mathrm{kJ} / \mathrm{mol})$

$\mathrm{R}=$ constant

$\mathrm{T}=$ temperature

While to find the value of coefficient of adsorbate distribution used equation as follows:

$$
\ln K_{D}=\frac{\Delta S}{R}-\frac{\Delta H}{R T}
$$

where :

$$
\begin{aligned}
& \mathrm{Kd}=\text { adsorbent distribution coefficient (qe / Ce) } \\
& \Delta \mathrm{H}=\text { enthalpy } \\
& \Delta \mathrm{S}=\text { entropy } \\
& \mathrm{R}=\text { constant } \\
& \mathrm{T}=\text { temperature }
\end{aligned}
$$

\section{RESULTS AND DISCUSSION}

\section{Characterization of Double Layer Hydroxides Using FT-IR Spectrophotometer}

Synthesis of double layer hydroxides was conducted using magnesium nitrate and aluminum nitrate. $\mathrm{M}^{2+}$ charged metal cations represent magnesium and aluminum represented by $\mathrm{M}^{3+}$ each of which is bound to an $\mathrm{OH}^{-}$anion. The result of the process of synthesis double layer hydroxides compound is a white solid which is further characterized by using FT-IR spectrophotometer.

The FT-IR spectrum of the double layer hydroxy material is presented in Figure 1. The widespread vibration peak between the $3800-300 \mathrm{~cm}^{-1}$ wavenumbers is the vibration of the $\mathrm{OH}$ strain within the structure of the double-layer hydroxy compound. The presence of a peak detected at the wave number $1635.5 \mathrm{~cm}^{-1}$ in the bend vibration of $\mathrm{OH}$. In the region of wavenumber $1381,1 \mathrm{~cm}^{-1}$, there is a vibration which is symmetrical stretching of nitrate and

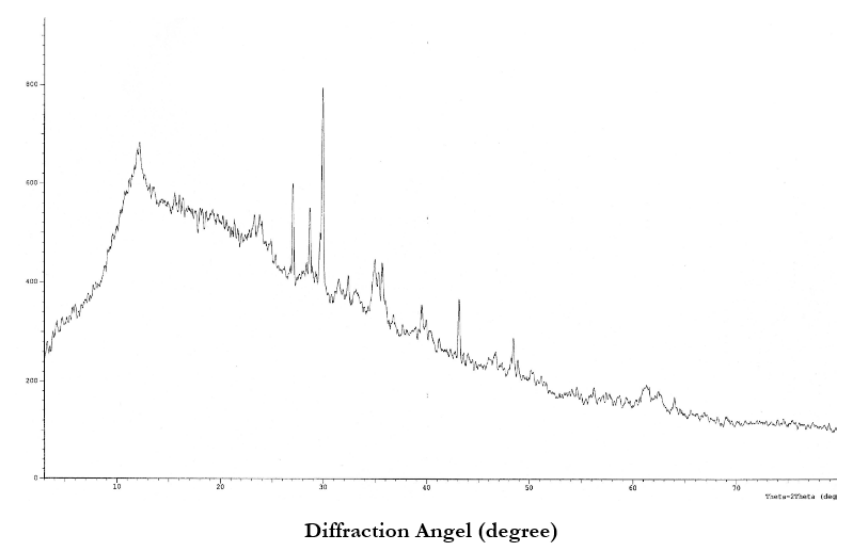

Figure 2. XRD powder pattern of $\mathrm{Mg} / \mathrm{Al}$ double layer hydroxides 
$671,2 \mathrm{~cm}^{-1}$ is nitrate bending vibration. In the wavenumber 408.9 $\mathrm{cm}^{-1}$ is the vibration of $\mathrm{Mg}-\mathrm{O}$ (Imron and Said, 2017).

\section{Characterization of Double Layer Hydroxides Using X-Ray Diffraction}

The double layer hydroxides material was characterized using $\mathrm{XRD}$ and the results are presented in Figure 2. Double layer hydroxy has a strong diffraction peak at $2 \theta$ value i.e. 11.70 with basal spacing $7.5 \dot{\mathrm{A}}$. The diffraction angles at $29^{\circ}, 27^{\circ}$ and $28^{\circ}$ are typical of the $\mathrm{Mg}-\mathrm{Al}$ double-layer hydroxy. According to Dolidovich and Palkovits (2015), the X-ray diffraction pattern showing the layered structure is in the $2 \theta$ diffraction of $10^{\circ}$ and $60^{\circ}$. The layered structure allows the anion to reside on the interlayer of the double layer hydroxy material, according to Brandl, et al. (2017) the peak in the $2 \theta$ diffraction pattern of $60^{\circ}$ indicates that the presence of anions on interlayers may be anion nitrate, carbonate, hydroxy or other anions. Layer double hydroxides then was used as adsorbent of procion red. The paramaters that influencing adsorption such as kinetic and thermodynamic was studied.

\section{Effect of Adsorption Time of Procion Red using Double} Layer Hydroxides as Adsorbent

Variation of adsorption contact time is done with the aim to know the effect of time between adsorbent on dye procion red as adsorbate. This adsorption was carried out by using a concentration of $60 \mu \mathrm{g} / \mathrm{L}$ of procion red dye with variation of adsorption time for 10, 20, 30, 40, 50, 60, 70, 80, and $90 \mathrm{~min}$ with the weight of each adsorbent used at $0.05 \mathrm{~g}$. The adsorption data on the adsorption time variation using the double layer hydroxy material is shown in Figure 3.

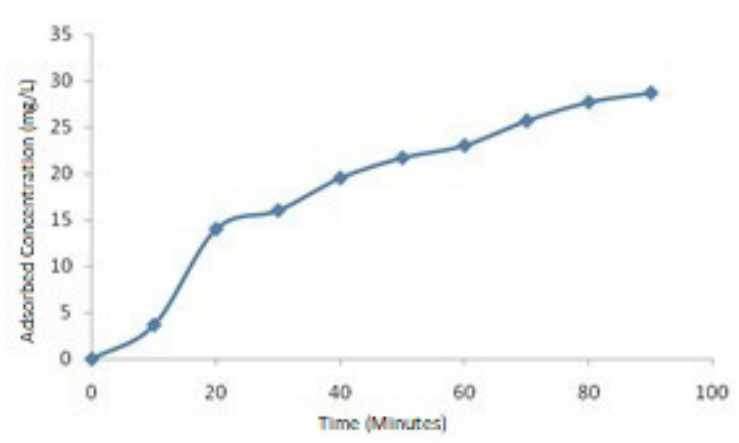

Figure 3. Effect of adsorption time of procion red on layer double hydroxides

Figure 3 shows the adsorption of the dye increases with increasing time of adsorption. This is because the longer the collision between adsorbent and adsorbate so it make the more adsorbate adsorbed by the adsorbent. At an optimum time of 90 minutes it appears that the amount of procion red dye adsorbed is $22.6 \mathrm{ppm}$.

The adsorption time data in Figure 3 is used to calculate the adsorption rate based on the Langmuir-Heinselwood in equation 1. The adsorption constant rate can be calculated as the slope of the $\ln (\mathrm{Co} / \mathrm{C}) / \mathrm{C}$ plot to $\mathrm{t} / \mathrm{C}$ as the line equation. The value of each slope is used as the adsorption rate constant $\left(\mathrm{k}_{1}\right)$ and the correlation coefficient $\left(\mathrm{R}^{2}\right)$ of the plot $(\mathrm{Co} / \mathrm{C}) / \mathrm{C}$. The correlation coefficient was obtained 0.97 indicates the existence of the Langmuir-Heinselwood equation. Adsorption rate of procion red on layer double hydroxides was 7.1 minutes $^{-1}$.
Effect of Temperature and Adsorption Concentration of Procion Red Dys with Adsorbent Double Layered Hydroxides

The effect of temperature and concentration of procion red dye adsorption by double layer hydroxides material adsorbent is done by varying the temperature and concentration of the procion red dye. The adsorbent of double layer hydroxides material was carried out with variation of adsorption temperature i.e. 30, 40, 50,60 , and $70{ }^{\circ} \mathrm{C}$. Variation of dye concentration of procion red by adsorbent of double layer hydroxy material using concentration 10, 20, 40, 70, and $100(\mathrm{mg} / \mathrm{L})$.

The curve of effect of adsorption temperature on the amount of procion red absorbed is presented in Figure4

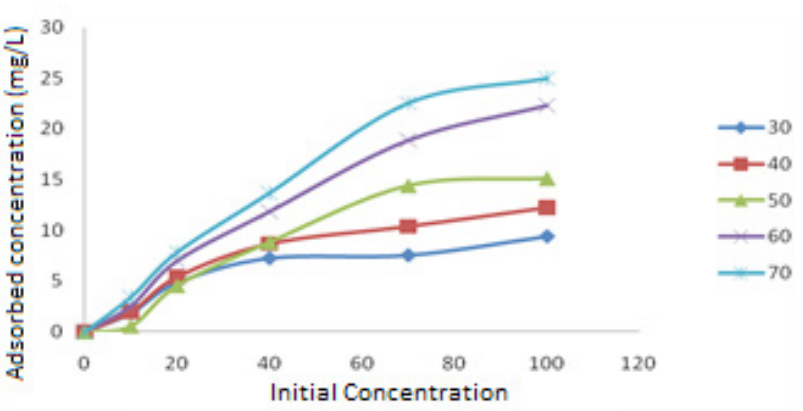

Figure 4. Effect of temperature and concentration of procion red dye on double layer hydroxides

From the Figure 4, it is seen that the adjacent point at the concentration of procion red dye $10 \mathrm{mg} / \mathrm{L}$ and $20 \mathrm{mg} / \mathrm{L}$. This is corralate to the increaseing of adsorption temperature does not result in a significant difference in the amount of procion red adsorbed significantly on the concentration of procion red $10 \mathrm{mg} / \mathrm{L}$ and 20 $\mathrm{mg} / \mathrm{L}$. For the concentrations of 40.70 , and $100 \mathrm{mg} / \mathrm{L}$, it is sufficient effect on the amount of dyestuff adsorbed on temperature variations. This phenomenon is also found in the study by (Kaur and Rajvir, 2016).

Furthermore, the value of enthalpy $(\Delta \mathrm{H})$ and entropy $(\Delta \mathrm{S})$ can be calculated as the slope and interserp of $1 / \mathrm{T}$ to $\ln \mathrm{Kd}$ as shown in equation 4 . The adsorption capacity (b) can be calculated by equation 2 . Table 1 shows the value of enthalpy $(\Delta \mathrm{H})$ and entropy $(\Delta S)$ increases with increasing procion red concentration for the $\mathrm{Mg} / \mathrm{Al}$ double layer hydroxides adsorbent. The energy value of adsorption (E) is calculated using equation 3 with equilibrium

Table 1 . Effect of concentration of procion red dye adsorption using double layer hydroxides

\begin{tabular}{lccc}
\hline Adsorbent & $\begin{array}{c}\text { Concentration } \\
(\mathrm{mg} / \mathrm{L})\end{array}$ & $\begin{array}{c}\Delta \mathrm{H} \\
(\mathrm{kJ} / \mathrm{mol})\end{array}$ & $\begin{array}{c}\Delta \mathrm{S} \\
(\mathrm{kJ} / \mathrm{mol})\end{array}$ \\
\hline double layer & 10 & 16.927 & 0.042 \\
hydroxides & 20 & 15.289 & 0.040 \\
& 40 & 18.299 & 0.047 \\
& 70 & 30.179 & 0.082 \\
\hline
\end{tabular}

Table 2. Effect of adsorption temperature of procion red dye on double layer hydroxides

\begin{tabular}{lccc}
\hline Adsorbent & $\begin{array}{c}\text { Temperature } \\
\left({ }^{0} \mathrm{C}\right)\end{array}$ & $\begin{array}{c}\mathrm{b} \\
(\mathrm{mg} / \mathrm{g})\end{array}$ & $\mathrm{E}(\mathrm{kJ} / \mathrm{mol})$ \\
\hline & 30 & 28.57 & 9.04 \\
Double layer & 40 & 27.02 & 8.69 \\
hydroxides & 50 & 90.90 & 11.07 \\
& 60 & 111.11 & 11.13 \\
& 70 & 125 & 10.80 \\
\hline
\end{tabular}


constant value $(K)$ obtained from equation 2. Table 2 shows the adsorption energy data (E) has a regular tendency with increasing temperature. Thus layer double hydroxides can be used as efficient adsorbent for procion red dye.

\section{CONCLUSION}

Procion red adsorption using layer double hydroxides resulted in adsorption rate $(\mathrm{k})$ of 7.1 minutes $^{-1}$. In general, enthalpy, entropy, and adsorption capacity was increased by increasing temperature adsorption and concentration of procion red dye.

\section{ACKNOWLEDGMENTS}

This results are a part of "Hibah Profesi" Project 2017. The authors thank to Sriwijaya University for support this research through "Dana PNBP Hibah Profesi 2017" and to Integrated Research Laboratory Sriwijaya University for research facilities.

\section{REFERENCES}

Asiabi. H., Yamini. Y., Shamsayei. M., Tahmasebi. E. (2017). Highly Selective and Efficient Removal and Extraction of Heavy Metals by Layered Double Hydroxides Intercalated with the Diphenylamine-4-Sulfonate: A Comparative Study. Chemical Engineering Journal, 323, 212-223.

Ba-Abbad. M., Takriff. M.S., Said. M., Benamor. A., Nasser. M.S., Mohammad. A.W. (2017). Photocatalytic Degradation of Pentachlorophenol Using ZnO Nanoparticles: Study of Intermediates and Toxicity. International Journal of Environemtal research, In Press. DOI:_10.1007/s41742-017-0041-3.

Brandl. M., Sayed. M.H., Riedel. I.H., Hocka. R., Gütay. L. (2017). In-situ XRD Investigation of Selenization of CZTS Nanoparticles. Journal of Alloys and Compounds, 714, 35-38.

Centi. G., Perathoner. S. (2008). Catalysis by Layered Materials : A Review. Microporous and Mesoporous Materials, 107, 3-15.
Corma. A. (1999). From Microporous to Mesoporous Molecular Sieve Materials and Their Use in Catalysis. Chemical Reviews, 1, 2373-2419.

Delidovich. I., Palkovits. R. (2015). Structure Performance orrelations of $\mathrm{Mg}-\mathrm{Al}$ Hydrotalcite Catalysts for the Isomerization of Glucose into Fructose. Journal of Catalysis, 327, 1-9.

Goodarzi. A.R., Fateh. S. N., Shekary. H. (2016). Impact of Organic Pollutants of the Macro and Micro Struture Responses of Na-Bentonite. Journal Applied Clay Science, 121, 17-28.

Hassani. K. E., Beakou. B.H., Kalnina. D., Pukani. E., Anouar. A. (2017). Effect of Morphological Properties of Layered Double Hydroxides on Adsorption of Azo Dye Methyl Orange: a Comparative Study. Applied Clay Science, 140, 124-131.

Imron. M., Said. M. (2017). Pillarization of Double Layer Hydroxides Using $\mathrm{H}_{3}\left[\alpha-\mathrm{PW}_{12} \mathrm{O}_{40}\right] \cdot \mathrm{nH}_{2} \mathrm{O}$ : Effect of Pillarization Time. Science \& Technology Indonesia, 2, 45-49.

Kaur. R., Rajvir. H, K. (2016). Electrochemically Degredation of Congo red from Aquos Solutions. Portugalle Acta, 3, 185-196.

Kim. H. J., Chu. H, J., Moon. J., Han. S, H., Shul. G, Y. (2009). Preparation of Heteropoly Acid Entraped in Nano Silica Matrix. Molecular Crystals and Liquid Crystals Journal, 371, 131134.

Rodrigues. C.S.D., Madeira. L.M., Boaventura. R.A.R. (2009). Optimization of the Azo Dye Procion Red H-EXL Degradation by Fenton's Reagent Using Experimental Design. Journal of Hazardous Materials, 164, 987-994.

Said. M., Palapa. N.R. (2016). Adsorption Of Congo Red Using $\mathrm{Mg} / \mathrm{Al}$ Hydrotalcite, Science \& Technology Indonesia, 2, 17-21.

Xie. W., Peng. H., Chen. L. (2006). Calcined Mg/Al Hydrotalcite as Solid based Catalysis for Methanolysis of Soybean Oil. Journal of Molecular Catalysis A: Chemical, 246, 24-32. 